\title{
Children's physical activity and parents' perception of the neighborhood environment: neighborhood impact on kids study
}

\author{
Karyn A Tappe ${ }^{1,2}$, Karen Glanz ${ }^{3}$, James F Sallis ${ }^{4,5}$, Chuan Zhou ${ }^{6,7}$ and Brian E Saelens ${ }^{6,7^{*}}$
}

\begin{abstract}
Background: Physical activity is important to children's physical health and well-being. Many factors contribute to children's physical activity, and the built environment has garnered considerable interest recently, as many young children spend much of their time in and around their immediate neighborhood. Few studies have identified correlates of children's activity in specific locations. This study examined associations between parent report of their home neighborhood environment and children's overall and location-specific physical activity.

Methods: Parents and children ages 6 to $11(n=724)$, living in neighborhoods identified through objective built environment factors as high or low in physical activity environments, were recruited from Seattle and San Diego metropolitan areas, 2007-2009. Parents completed a survey about their child's activity and perceptions of home neighborhood environmental attributes. Children wore an accelerometer for 7 days. Multivariate regression models explored perceived environment correlates of parent-reported child's recreational physical activity in their neighborhood, in parks, and in general, as well as accelerometry-based moderate-to-vigorous activity (MVPA) minutes.
\end{abstract}

Results: Parent-reported proximity to play areas correlated positively with both accelerometery MVPA and parentreported total child physical activity. Lower street connectivity and higher neighborhood aesthetics correlated with higher reported child activity in the neighborhood, while reported safety from crime and walk and cycle facilities correlated positively with reported child activity in public recreation spaces.

Conclusions: Different aspects of parent's perceptions of the neighborhood environment appear to correlate with different aspects of children's activity. However, prioritizing closer proximity to safe play areas may best improve children's physical activity and, in turn, reduce their risk of obesity and associated chronic diseases.

Keywords: Built environment, Perceptions, Recreation, Play

\section{Background}

Neighborhood environments may play an important role in children's planned and incidental physical activity [1,2]. Neighborhood built environment comprises buildings, roads, open spaces, and sidewalks [3] and provide opportunities or barriers to physical activity [4]. The neighborhood social environment, as it relates to physical activity, includes personal safety from crime and traffic [4]. Because children have less autonomy

\footnotetext{
* Correspondence: brian.saelens@seattlechildrens.org

${ }^{6}$ Seattle Children's Research Institute, P.O. Box 5371, Seattle, WA 98145, USA 7Department of Pediatrics, School of Medicine, University of Washington, Seattle, USA

Full list of author information is available at the end of the article
}

than adults, these neighborhood environmental characteristics, as well as their parents' perceptions of these characteristics, may have particular impact on their physical activity $[5,6]$. However, in a recent systematic review, only $30 \%$ of associations between parent perceptions of the environment and children's activities was significant in the anticipated direction. The most consistently supported predictor of children's reported physical activity was pedestrian safety structures (e.g., crosswalks). None of the environmental attributes were consistently related to children's objectively-measured physical activity [2].

One possible reason for inconsistencies is that few studies have attempted to relate environmental attributes

\section{Biomed Central}

(c) 2013 Tappe et al.; licensee BioMed Central Ltd. This is an Open Access article distributed under the terms of the Creative Commons Attribution License (http://creativecommons.org/licenses/by/2.0), which permits unrestricted use, distribution, and reproduction in any medium, provided the original work is properly cited. 
to children's activity in specific locations. Neighborhood attributes may be more related to physical activity in specific locations in the neighborhood, whereas overall physical activity may be influenced by a broader range of neighborhood, school, community, family, and other factors. Active transport has been the topic most frequently studied in relation to location of activity (e.g., in the neighborhood [7-9]). Other research has only considered inside versus outside play [10] and activity in school play areas [11]. More detailed studies of environmental correlates of children's physical activity in specific locations may be informative, particularly for public policy and urban planning projects that target specific transit and recreation-related infrastructure.

The present study examines associations between parent reports of their neighborhood environment and children's activity within the neighborhood and in parks. Because measurement modality for physical activity influences findings [2], the present study examined both parent-reported and accelerometer-assessed children's physical activity. The parent reports herein emphasize children's recreational activity.

\section{Methods}

\section{Context}

The analyses presented here are based on the baseline data of the Neighborhood Impact on Kids (NIK) Study, an NIH-funded longitudinal, observational cohort study of children and their parents in Seattle/King County, WA and San Diego County, CA. NIK was designed to evaluate the association of neighborhood environment factors with children and parent's weight status and weight-related behaviors, including physical activity [12]. This study was approved by the Institutional Review Boards at Seattle Children's Hospital and San Diego State University.

\section{Participants}

Participants were selected using a two-stage stratified cluster sampling. In the first stage, census blocks (hereafter, "neighborhoods") were selected based on their physical activity opportunities, categorized as having high versus low physical activity opportunities based on Geographic Information Systems (GIS)-generated measures. In the second stage, households within the identified neighborhoods were contacted using information from a commercial marketing firm. Participants consisting of one child aged 6 to 11 and one parent/caregiver per household were recruited. Children and parents were required to live in one of the identified neighborhoods; be able to engage in at least moderate-intensity physical activity; not have underlying medical conditions associated with obesity (e.g., Cushing's syndrome) or be actively involved in medical treatment that has substantive impact on growth (e.g., growth hormone treatment). Further details on both neighborhood and individual inclusion/exclusion can be found elsewhere [12]. The eligible block groups have been analyzed and found similar to the county as a whole [12].

\section{Recruitment and response rates}

Participants were recruited between September 2007 and January 2009. A total of 8,616 recruitment letters were sent, and 4,975 households were contacted by phone to explain the study and assess eligibility and willingness to participate. In San Diego County, 366 families consented to participate, and in Seattle/King County, 372 consented (14.6\% consent rate). A total of 730 families from both sites completed their initial visit.

\section{Procedures}

At an office or home visit, parents provided consent and children provided assent. Parents and children had their height, weight and waist circumference measured. They were then provided with an accelerometer and instructed on how to have the child wear it. The parent was asked to complete a 25-page survey (online or on paper) that included questions about the neighborhood and their child's physical activities. The study staff called participants once during the week following the visit to answer any questions and encourage daily wearing of the accelerometer.

\section{Measures}

\section{Accelerometer-measured children's physical activity}

Child physical activity was objectively measured by the GT1M Actigraph ${ }^{\circledR}$ accelerometer [13]. Children were asked to wear the accelerometer for seven consecutive days, at least 10 hours per day during their waking hours. The accelerometry data were downloaded and screened for completeness and possible irregularities/ malfunction upon return by mail. A valid wearing/waking hour included hours without any instances of 20 minutes of consecutive zero activity count epochs. Children were asked to wear the accelerometer again if $<6$ days of valid data (minimum of 10 hours per day) were recorded (102 children, or $13.8 \%$ of sample).

We calculated average minutes of moderate-to-vigorous physical activity (MVPA) per day using age-based 3-MET cut-points [14] and the Evenson MVPA calculation method [15], as they can produce quite different results and the definitive cut-point for children has not been established.

\section{Neighborhood environment survey}

Table 1 provides descriptions of survey sections analyzed in the present study (see [16] for the full questionnaire). Neighborhood environment perception items were taken from previously-evaluated measures [17-19]. Most of the survey subscales have shown good internal consistency 
Table 1 Subscales on the NIK Self-Report Survey used in the present report, with descriptions, scoring, and internal consistency, Seattle and San Diego, 2007-2009

\begin{tabular}{|c|c|c|c|c|}
\hline Name & \# Items & Example items, response options, and scale development & Alpha & $\begin{array}{l}\text { Mean (S.D.) or } \\
\text { proportions }\end{array}$ \\
\hline \multicolumn{5}{|l|}{ Predictor variables* } \\
\hline \multirow{5}{*}{$\begin{array}{l}\text { Getting Around in } \\
\text { Your Neighborhood[19] }\end{array}$} & \multirow[t]{5}{*}{22 (5 subscales) } & \multirow{5}{*}{$\begin{array}{l}\text { Subjective evaluation of ease or difficulty of traveling in neighborhood } \\
\text { due to various issues: "Parking is difficult; ... There are sidewalks on } \\
\text { most streets; ... There are trees along streets." Each item scored on } \\
\text { 4-point Likert from } 1 \text { (Strongly Disagree) to } 4 \text { (Strongly Agree). } \\
\text { Subscales: i) street connectivity; ii) walking/cycling facilities; iii) } \\
\text { neighborhood aesthetics; iv) traffic safety; v) safety against crime. } \\
\text { Subscales adapted from previous research [19] }\end{array}$} & Scale i: 42 & $2.76(0.76)$ \\
\hline & & & Scale ii: 70 & $2.53(0.88)$ \\
\hline & & & Scale iii: .81 & $3.03(0.66)$ \\
\hline & & & Scale iv: .60 & $2.37(0.51)$ \\
\hline & & & Scale v: .82 & $2.07(0.66)$ \\
\hline \multirow[t]{2}{*}{ Proximity to Locations[19] } & \multirow[t]{2}{*}{25 (2 subscales) } & \multirow[b]{2}{*}{$\begin{array}{l}\text { "About how long would it take you to walk from your home to the } \\
\text { nearest places listed?" Scale: from } 1 \text { ( } 1-5 \text { minutes) to } 5(31+\text { minutes) } \\
\text { or } 6 \text { (Don't know). Reverse recoded per [21] to indicate proximity to } \\
\text { locations. Subscales: i) Stores/services and ii) Recreation areas } \\
\text { (swimming pool; indoor recreation facility; water recreation areas; } \\
\text { trails; basketball court; other fields/courts; parks; playgrounds; schools } \\
\text { with available facilities). }\end{array}$} & Scale i: .92 & $2.67(0.92)$ \\
\hline & & & Scale ii: .84 & $2.55(0.82)$ \\
\hline \multirow{2}{*}{$\begin{array}{l}\text { Barriers to Walking } \\
\text { and Biking[17] }\end{array}$} & \multirow[t]{2}{*}{14 (2 subscales) } & \multirow{2}{*}{$\begin{array}{l}\text { "It is difficult for my child to walk or bike to the closest park or playground } \\
\text { because... there are no sidewalks; ...the route is boring; ... my child } \\
\text { has too much stuff to carry." Scale: 4-point Likert from } 1 \text { (Strongly Disagree) } \\
\text { to } 4 \text { (Strongly Agree).Subscales: i) Logistics ii) Route characteristics. }\end{array}$} & Scale i: .77 & $1.62(0.55)$ \\
\hline & & & Scale ii: 79 & $1.91(0.70)$ \\
\hline \multirow{2}{*}{$\begin{array}{l}\text { Barriers to Activity in } \\
\text { Your Neighborhood[17] }\end{array}$} & \multirow[t]{2}{*}{9 (2 subscales) } & \multirow{2}{*}{$\begin{array}{l}\text { "It is difficult for my child to be active in the local park or the streets/ } \\
\text { neighborhood near our home because... there is no choice of } \\
\text { activities; ...there is no equipment; ... it is not safe because of traffic." } \\
\text { Scale: 4-point Likert from } 1 \text { (Strongly Disagree) to } 4 \text { (Strongly Agree). } \\
\text { Subscales: i) Perceived lack of appropriate play areas; ii) Crime activity. }\end{array}$} & Scale i: 81 & $1.81(0.67)$ \\
\hline & & & Scale ii: 72 & $1.57(0.73)$ \\
\hline \multicolumn{5}{|l|}{ Outcome Measures** } \\
\hline Neighborhood activity[17] & 4 & $\begin{array}{l}\text { "How often is your child physically active: In your driveway or alley? } \\
\text {.. In a local street, sidewalk, or vacant lot?" Options: } 1 \text { (Never) to } 6 \\
\text { (4 days/week or more). Recoded to indicate number of times per } \\
\text { month, and numeric responses summed.The total was dichotomized } \\
\text { at } 4 \text { days per week ( } 16 \text { days per month) to indicate physical activity } \\
\text { in neighborhood. }\end{array}$ & .76 & NA \\
\hline Park activity[17] & 4 & $\begin{array}{l}\text { "How often is your child physically active in/at the following locations: } \\
\text { Trails/paths? ...Small public park? ... . arge public park? . . . Open space?" } \\
\text { Options: } 1 \text { (Never) to } 6 \text { ( } 4 \text { times/week or more). All } 4 \text { items recoded, } \\
\text { summed and dichotomized at } 2+\text { days per week to indicate any } \\
\text { activity in parks/trails/open areas. }\end{array}$ & .67 & NA \\
\hline $\begin{array}{l}60+\text { minute activity days } \\
\text { (outside of school)[17] }\end{array}$ & 2 & $\begin{array}{l}\text { "How many days is/was your child physical activity for a total of at } \\
\text { least } 60 \text { minutes per day (do not include school based activities)?" } \\
\text { (Scored: 0-7 days). Two items: i) the past seven days; ii) Over a } \\
\text { typical week. Averaged and then dichotomized at } 5 \text { days/week. }\end{array}$ & .93 & NA \\
\hline
\end{tabular}

$\mathrm{NA}=$ Not applicable due to dichotomous nature of variable.

* Note: All predictor variables were directionally coded so that a higher number indicated an environment more conducive to being physically active.

* See [16] for full questionnaire set.

and test-retest reliability $[17,19,20]$. Items addressed various aspects of the built and social environments, such as proximity to destinations, inaccessibility of recreation facilities, presence of suitable play areas, street connectivity, aesthetics, traffic safety, and crime safety [21]. The internal consistency of the subscales used in the present study was confirmed using Cronbach's alpha.

\section{Physical activity survey}

Parents completed three survey sections about their children's physical activity (see Table 1) [17]. First, frequency of children's physical activity was assessed in their driveway/alley, neighborhood yards or driveways, streets or sidewalks, and in a nearby cul-de-sac or dead-end street (hereafter grouped into "neighborhood activity"). Second, activity in parks and park-like environments (hereafter grouped into "park activity") was assessed through four questions inquiring about frequency of physical activity on paths/trails, at small public parks/ playgrounds, at large public parks, or in open spaces.

For each category of activity (neighborhood activity or park activity), the ordinal responses were rescaled and summed to indicate number of times per month active in any possible combination of the specific locations that made up neighborhood or park activity (ex. twice a week active in alley plus twice a week active in driveway), and 
then dichotomized at 1$)$ four times per week (16 times per month) or more (yes or no) for neighborhood activity and 2) two times per week or more (yes or no) for park activity. These scales were dichotomized because they were ordinal rather than interval scales, and thus not suitable for use as continuous variables. The cut points represent the approximate median value (rounded to nearest whole day) for each one of these variables, as no more theoretically-justified cut point has been established for such location-specific activity measurement.

In the third survey section, parent-reported days per week that their child performed 60 or more minutes of physical activity was assessed using two items that were averaged [22]. This average was dichotomized at 5 or more days per week of activity, the median value reported. It is referred to hereafter as " $60+$ minute activity days."

\section{Physical activity environment}

Study census blocks ("neighborhoods") were selected based on a multi-dimensional assessment of physical activity opportunities generated from parcel and street network data in a GIS to evaluate within each region each neighborhood's (a) built environment related to walkability (weighted sum of z-scores by region for residential density, intersection density, land use mix, retail floor area ratio) [23] and (b) proximity of a "high quality" park. "High physical activity neighborhoods" were those with an above median walkability index score and at least one park within the neighborhood or the $1 / 4$ mile buffer around the neighborhood that scored high on a park quality audit (Environmental Assessment of Public Recreation Spaces) $[16,24]$. "Low physical activity neighborhoods" were below these thresholds (see [12]). This dichotomous variable was included in all multivariate models.

\section{Household demographics}

Demographics were included as covariates in the multivariate models: child sex, age, race (white or non-white due to low numbers of most non-African American minority groups), BMI percentile, ethnicity (Hispanic or not), and household income $(<\$ 50,000 / y r$, $\$ 50-\$ 100,000 / \mathrm{yr}$ and $\$ 100,000+/ \mathrm{yr})$.

\section{Analyses}

Linear and logistic bivariate models were calculated for continuous and dichotomous outcomes respectively using single predictor regression models. Then, the three dichotomized outcome measures (neighborhood activity at 4 times or more per week [yes/no], park activity at 2 times or more per week [yes/no], and $60+$ minutes of physical activity at 5 days per week [yes/no]) were analyzed with multivariate logistic regression models. Two groups of predictors were considered: demographics and neighborhood environment factors. Given the large number of potential predictors, a manual, backwards stepwise regression approach was used, starting with an initial model of all possible predictors ("full model") and manually dropping the least significant term one at a time, then comparing the reduced model to the previous model using the likelihood ratio test. If the model fit was significantly worse, the removed term was returned and the next least significant term examined, until no further term could be removed without significant reduction in model goodness of fit. Therefore, non-significant covariates that stabilized the model fit were retained. The likelihood ratio test for this "final" model relative to the null model (intercept only) is reported.

Average MVPA minutes per day by accelerometer was treated as a continuous outcome and analyzed with multiple linear regression; skewness and kurtosis were compared against existing standards [25], and indicated no need for transformation of the outcome variable. The final models (one based on 3+ MET cut points and one based on Evenson cut points) were identified by a similar manually-performed backwards stepwise procedure as for the logistic regression models.

Because participants were recruited from particular neighborhoods that met our inclusion criteria, we evaluated the data for clustering effects that might necessitate multi-level modeling. The families were recruited from a large number of neighborhoods $(n=310)$ that are not necessarily geographically close. The numbers of families from the same neighborhood tend to be small (mean: 2.35 , range $1-16$ ); $81 \%$ of the neighborhoods had three or fewer participating families (38\% had only one family). Therefore we did not expect a clustering effect among the families. The intra-class correlation (ICC) for MVPA by neighborhood was only .06. As a result, multi-level modeling was not deemed appropriate and we report results based on participant-level, fixed effects models only.

All statistical analyses were performed using the SPSS statistical software version 19.0 (IBM, Armonk, NY). $\mathrm{P}<.05$ was considered statistically significant.

\section{Results}

\section{Participant characteristics}

The average age of children in the study was $9.14 \pm 1.56$; $81.6 \%$ were white and $16.5 \%$ reported themselves as Latino. Sex distribution was equal (49.3\% female). The average BMI percentile score of the children was $62.24 \pm$ 27.16; $15.5 \%$ were classified as overweight (85-94\% BMI percentile) and $14.4 \%$ as obese (95\% + BMI percentile). Family income was reported above $\$ 100,000$ per annum by $49.4 \%$ and below $\$ 50,000$ for $13.6 \%$ of families.

Children spent an average of 146.0 minutes $(\mathrm{SD}=53.4)$ based on the 3+ METS cut points and 46.7 minutes $(\mathrm{SD}=21.4)$ based on the Evenson cut point in MVPA per 
day based on the accelerometer, suggesting a predominance of low-moderate physical activity not captured by the higher Evenson cut points.

\section{Physical activity and reported environment}

Parent-reported outcomes: neighborhood physical activity

Table 2 shows the univariate, full, and final multivariate models on parent-reported child neighborhood activity. Four neighborhood environment and three demographic variables were in the final model $\left(\mathrm{x}^{2}=41.04, \mathrm{p}<.001\right)$, four of which were statistically significant. Girls were less likely to be active than boys $(\mathrm{OR}=0.68)$. Lower street connectivity $(\mathrm{OR}=0.77)$ and better aesthetics $(\mathrm{OR}=1.57)$ increased the odds of being active at least 4 days a week in the neighborhood, while perceived lack of suitable play areas lowered the odds of being active $(\mathrm{OR}=0.74)$.

\section{Parent-reported outcomes: physical activity in park areas}

As seen in Table 3, the final model for reported park activity comprised seven neighborhood environment and three demographic variables $\left(\chi^{2}=64.87, \mathrm{p}<.001\right)$, six of which were statistically significant. Being Hispanic $(\mathrm{OR}=1.56)$, better reported safety from crime $(\mathrm{OR}=1.30)$, higher neighborhood aesthetics $(\mathrm{OR}=1.38)$, better walking/cycling facilities $(\mathrm{OR}=1.40)$, and closer proximity to play areas $(\mathrm{OR}=1.22)$ were significantly associated with increased odds of reported park activity on at least 2 days per week. Reported lack of appropriate play areas was significantly associated with lower odds of reported park activity $(\mathrm{OR}=0.74)$.

\section{Parent-reported outcomes: $60+$ minute activity days}

The final model for reportedly engaging in $60+$ activity minutes at least 5 days per week contained three neighborhood environment variables and four demographic variables $\left(x^{2}=34.41, p<.001\right.$ (see Table 4 ), three of which were statistically significant. Reported closer proximity to play areas $(\mathrm{OR}=1.29)$ was the only environment variable significantly associated with greater odds of children's $60+$ activity minutes per day $5+$ days per week. Child

Table 2 Logistic regression: odds of 4+ days of parent-reported children's neighborhood activity as predicted by parent-reported demographics and neighborhood characteristics

\begin{tabular}{|c|c|c|c|c|c|c|}
\hline & \multirow{2}{*}{$\begin{array}{l}\text { Univariate model } \\
\text { OR }\end{array}$} & \multirow[b]{2}{*}{$P$} & \multirow{2}{*}{$\begin{array}{c}\text { Full model } \\
\text { OR }\end{array}$} & \multirow[b]{2}{*}{$P$} & \multicolumn{2}{|c|}{ Final model } \\
\hline & & & & & OR $[95 \% \mathrm{Cl}]$ & $P$ \\
\hline \multicolumn{7}{|l|}{ Demographics (reference category) } \\
\hline Child race(White) & 1.06 & .75 & 1.19 & .41 & & \\
\hline Child age & 0.92 & .09 & 0.91 & .08 & $0.91[0.82-1.01]$ & .08 \\
\hline Child sex (M) & 0.73 & .04 & 0.67 & .01 & $0.68[0.49-0.93]$ & .02 \\
\hline Hispanic (N) & 0.81 & .30 & 0.85 & .48 & & \\
\hline Child's BMI \% & 1.00 & 69 & 1.00 & .41 & & \\
\hline Household income $<\$ 50,000(\mathrm{~N})$ & 0.76 & .21 & 0.90 & .70 & $0.87[0.54-1.41]$ & .57 \\
\hline Household income $\$ 50-\$ 100,000(\mathrm{~N})$ & 0.87 & .36 & 0.90 & .56 & $0.91[0.65-1.30]$ & .62 \\
\hline \multicolumn{7}{|l|}{ Neighborhood environment } \\
\hline Physical activity environment (GIS) & 0.83 & .23 & 0.79 & .20 & $0.84[0.60-1.16]$ & .29 \\
\hline Safety from crime & 1.17 & .17 & 0.90 & .47 & & \\
\hline Traffic safety & 1.77 & $<.001$ & 1.46 & .06 & & \\
\hline Street connectivity & 0.82 & .05 & 0.76 & .02 & $0.77[0.62-0.96]$ & .03 \\
\hline Neighborhood aesthetics & 1.68 & $<.001$ & 1.47 & .01 & $1.57[1.21-2.03]$ & $<.01$ \\
\hline Walk/cycle facilities & 1.05 & .60 & 0.99 & .94 & & \\
\hline Proximity to stores & 1.00 & .96 & 0.94 & .63 & & \\
\hline Proximity to play areas & 1.19 & .07 & 1.17 & .29 & & \\
\hline Barriers to walking/biking: Logistics & 0.68 & $<.01$ & 0.85 & .40 & & \\
\hline Barriers to walking/biking: Route & 0.75 & $<.01$ & 1.11 & .55 & & \\
\hline Barriers to activity: Perceived lack of appropriate play areas & 0.64 & $<.001$ & 0.79 & .12 & $0.74[0.58-0.95]$ & .02 \\
\hline Barriers to activity: Crime & 0.81 & .04 & 1.10 & .48 & & \\
\hline Constant & & & 2.00 & .54 & 4.35 & .05 \\
\hline
\end{tabular}

$N=673$, Seattle and San Diego, 2007-2009.

Percent of cases correctly classified with this model: $63.5 \%$.

OR Odds ratio.

GIS Geographic Information Systems data. 
Table 3 Logistic regression: odds of $2+$ days of parent-reported children's park activity as explained by parent-reported demographics and neighborhood environment

\begin{tabular}{|c|c|c|c|c|c|c|}
\hline & Univariate & & Full model & & Final model & \\
\hline & OR & $P$ & OR & $P$ & OR $[95 \% \mathrm{Cl}]$ & $P$ \\
\hline \multicolumn{7}{|l|}{ Demographics (reference category) } \\
\hline Race (White) & 0.88 & .50 & 0.89 & .59 & & \\
\hline Age & 0.99 & .79 & 0.97 & .61 & & \\
\hline $\operatorname{Sex}(M)$ & 1.05 & .73 & 0.94 & .71 & & \\
\hline Hispanic (N) & 1.49 & .05 & 1.57 & .06 & $1.56[0.99-2.45]$ & .05 \\
\hline Child's BMI percentile & 1.00 & .15 & 1.00 & .20 & & \\
\hline Household income $<\$ 50,000(\mathrm{~N})$ & 1.14 & .55 & 1.30 & .34 & $1.17[0.70-1.98]$ & .55 \\
\hline Household income $\$ 50-\$ 100,000(\mathrm{~N})$ & 1.08 & .64 & 1.21 & .30 & $1.16[0.82-1.65]$ & .41 \\
\hline \multicolumn{7}{|l|}{ Neighborhood environment } \\
\hline Physical activity environment (GIS) & 1.34 & .05 & 1.08 & .66 & $1.09[0.78-1.53]$ & .61 \\
\hline Safety against crime & 1.35 & .01 & 1.23 & .14 & $1.30[1.00-1.67]$ & .05 \\
\hline Street connectivity & 1.08 & .42 & 0.91 & .43 & & \\
\hline Neighborhood aesthetics & 1.82 & $<.001$ & 1.39 & .02 & $1.38[1.06-1.80]$ & .02 \\
\hline Traffic safety & 1.87 & $<.001$ & 0.93 & .72 & & \\
\hline Walk and cycle facilities & 1.59 & $<.001$ & 1.49 & $<.001$ & $1.40[1.16-1.71]$ & .001 \\
\hline Proximity to stores & 1.31 & .001 & 1.01 & .94 & & \\
\hline Proximity to play areas & 1.55 & $<.001$ & 1.24 & .13 & $1.22[0.98-1.53]$ & .07 \\
\hline Barriers to walking/ cycling: logistics & 0.65 & .002 & 0.84 & .36 & & \\
\hline Barriers to walking/ cycling: route & 0.59 & $<.001$ & 1.08 & .67 & & \\
\hline Barriers to activity: perceived lack of appropriate play areas & 0.58 & $<.001$ & 0.80 & .15 & $.74[0.57-0.96]$ & .03 \\
\hline Barriers to activity: crime & 0.73 & .003 & 0.86 & .25 & & \\
\hline Constant & & & 0.31 & .31 & .09 & .002 \\
\hline
\end{tabular}

$\mathrm{N}=676$, Seattle and San Diego, 2007-2009.

Percent of cases correctly classified with this model: 63.5 .

OR Odds ratio.

GIS Geographic Information Systems data.

age and sex also were significant correlates such that girls $(\mathrm{OR}=0.57)$ and older children $(\mathrm{OR}=0.88)$ were less likely to reportedly engage in this level of activity.

\section{Accelerometry-measured MVPA minutes}

The 3-MET cut point was used for the main analysis, and the multivariate linear model explained $49 \%$ of the variance in accelerometer-based MVPA $\left(\mathrm{F}_{3,710}=227.88\right.$, $\mathrm{p}<.001$ ) (see Table 5), with only one neighborhood and two demographic factor retained in the model. Accelerometry MVPA minutes was positively related to greater reported proximity to play areas $(B=4.12, \mathrm{p}<.05)$. Younger age was associated with higher MVPA minutes $(B=-22.44, p<.001)$ and males were more active than females $(\mathrm{B}=-25.64, \mathrm{p}<.001)$. Use of the Evenson cut point $\left(\mathrm{F}_{6,687}=23.24, \mathrm{p}<.001\right)$ explained $17 \%$ of the variance in MVPA and identified two additional significant correlates: lower BMI percentile $(\mathrm{B}=-0.08, \mathrm{p}<.05)$ and higher household income (using two dummy variables, ps $<.05)$ related to more physical activity.

\section{Discussion}

Several reported neighborhood environment correlates were found for child physical activity in the neighborhood, supporting the idea that stronger correlates will be identified for behaviors if the contexts of the correlates and behaviors are aligned $[2,26,27]$. Higher probability of children being reported active in the neighborhood was related to lower reported street connectivity (e.g., more cul-de-sacs), as found in another recent study [28]. Low connectivity reduces traffic volumes, providing safer neighborhood places to play. This finding contrasts with higher rates of transport-based physical activity among adults and children living in neighborhoods with higher street connectivity, such as more child active travel to/ from school, particularly in low traffic areas [29]. Because adults are not likely to play in the cul-de-sacs and alleys like their children, these findings seem to present a tradeoff between child activity and adult activity based on physical environment. These findings together highlight the importance of examining specific types of 
Table 4 Logistic regression: odds of 5+ days per week of parent-reported overall child activity as explained by parent-reported demographics and neighborhood environment

\begin{tabular}{|c|c|c|c|c|c|c|}
\hline & Univariate model & & Full model & & Final mod & \\
\hline & OR & $P$ & OR & $P$ & OR $[95 \% \mathrm{Cl}]$ & $P$ \\
\hline Demographics (reference category) & & & & & & \\
\hline Child Race (White) & 0.94 & .76 & .98 & .94 & & \\
\hline Child Age & 0.88 & .01 & .89 & .02 & $0.88[0.80-0.98]$ & .02 \\
\hline Child Sex (M) & 0.60 & .001 & .54 & $<.01$ & $0.57[0.41-0.77]$ & $<.01$ \\
\hline Hispanic (N) & 0.76 & .19 & .83 & .43 & $0.83[0.53-1.28]$ & .40 \\
\hline Child's BMI percentile & 0.99 & .69 & 1.00 & .40 & & \\
\hline Household income $<\$ 50,000(\mathrm{~N})$ & 0.81 & .33 & .93 & .80 & $0.83[0.50-1.38]$ & .47 \\
\hline Household income $\$ 50-100,000(\mathrm{~N})$ & 0.83 & .22 & .86 & .40 & $0.83[0.59-1.17]$ & .28 \\
\hline Neighborhood environment & & & & & & \\
\hline Physical activity environment (GIS) & 1.14 & .39 & 1.11 & .56 & $1.04[0.75-1.44]$ & .81 \\
\hline Safety against crime & 1.05 & .65 & .84 & .23 & & \\
\hline Street connectivity & 1.00 & .99 & 1.02 & .85 & & \\
\hline Neighborhood aesthetics & 1.33 & .01 & 1.21 & .16 & & \\
\hline Traffic safety & 1.49 & .01 & 1.48 & .05 & $1.31[0.96-1.80]$ & .09 \\
\hline Walk/cycle facilities & 0.98 & .82 & .89 & .28 & & \\
\hline Proximity to stores & 1.08 & .32 & .90 & .41 & & \\
\hline Proximity to play areas & 1.33 & .002 & 1.46 & .01 & $1.29[1.05-1.60]$ & .02 \\
\hline Barriers to walking/cycling: logistics & 0.81 & .14 & .96 & .83 & & \\
\hline Barriers to walking/cycling: route & 0.85 & .85 & 1.22 & .26 & & \\
\hline Barriers to activity: perceived lack of appropriate play areas & 0.79 & .04 & 1.00 & .99 & & \\
\hline Barriers to activity: crime & 0.82 & .06 & .89 & .39 & & \\
\hline Constant & & & .78 & .82 & 0.99 & .98 \\
\hline
\end{tabular}

Percent of cases correctly classified with this model: 58.5 .

OR Odds Ratio.

GIS Geographic Information Systems data. Note: For ease of discussion in the text, the reciprocal of the odds ratio (1/OR) is sometimes reported. $(N=675)$.

physical activity (and subgroups within the population such as children versus adults) in relation to the environments in which the activity does or could occur, to know where best to target limited resources for public policy or urban planning projects. Creative planning solutions could allow parents and families to engage in active transportation to work, school, and other destinations allowed by better street connectivity while providing opportunities for children's unstructured play in the neighborhood either in streets (e.g., traffic calming strategies) or by providing other proximal spaces for active play (e.g., more playgrounds).

As with adults' recreational physical activity [30], we found that aesthetics were related to more child neighborhood physical activity. Favorable aesthetics may improve the enjoyment of being active in neighborhoods. However, Limstrand, 2008 [31] summarized the limited literature on this topic and found that two out of three studies reported no association between aesthetics and children's physical activity level. Another review found little relation between vegetation and children's reported activity [2]. Attractive buildings and gardens may have provided a sense of order for our particular sample of parents, making them more comfortable to let their children play and be active outside.

More frequent children's park activity was associated with better safety from crime, aesthetics, walking/cycling facilities, and suitable play area availability. Prior evidence highlights the importance to children's physical activity of having better accessibility to play areas [19,32]. Regarding aesthetics, we found previously that neighborhood aesthetics were perceived as higher by parents of children with more frequent park-based physical activity [19]. This prior study however found no relation between neighborhood safety from crime and park activity. Differences in sample characteristics and the types of urban areas and neighborhood environments may explain this discrepancy.

Proximity to play areas was the only correlate of total physical activity in the present study, and it applied to parent-reported child overall activity as well as to child accelerometer-based MVPA (both scoring methods). 
Table 5 Linear regression: pediction of accelerometry-based minutes of MVPA per day from parent-reported demographics and neighborhood environment

\begin{tabular}{|c|c|c|c|c|}
\hline Model & $\begin{array}{c}\text { Univariate models } \\
\text { for } 3 \text { MET cut point } \\
\text { B }\end{array}$ & $\begin{array}{c}\text { Full model for } \\
3 \text { MET cut point } \\
\text { B }\end{array}$ & $\begin{array}{l}\text { Final model } \\
\text { for } 3+\text { METs } \\
\text { B }[95 \% \mathrm{Cl}]\end{array}$ & $\begin{array}{c}\text { Final model using } \\
\text { Evenson cut points } \\
\text { B }[95 \% \mathrm{Cl}]\end{array}$ \\
\hline \multicolumn{5}{|l|}{ Demographics } \\
\hline Child Race (White) & -3.25 & 1.39 & & \\
\hline Child Age & $-22.38^{* *}$ & $-22.60^{* *}$ & $-22.44^{* *}[-24.24--20.64]$ & $-2.57^{* *}[-3.51--1.63]$ \\
\hline Child Sex (F) & $-29.40^{* *}$ & $-26.80^{* *}$ & $-25.64^{* *}[-31.26--20.01]$ & $-14.23^{* *}[-17.19--11.27]$ \\
\hline Hispanic (Y) & -5.34 & -0.93 & & \\
\hline Child's BMI percentile & 0.03 & -0.06 & & $-0.08^{*}[-0.13--0.03]$ \\
\hline Household income $<\$ 50,000(Y)$ & -8.73 & -6.64 & & $-4.97^{*}[-9.49--0.45]$ \\
\hline Household income $\$ 50-100,000(Y)$ & -3.60 & -3.09 & & $-4.24^{*}[-7.44--1.04]$ \\
\hline \multicolumn{5}{|l|}{ Neighborhood Environment } \\
\hline Physical activity environment (GIS) & 2.94 & 3.52 & & \\
\hline Safety against crime & -0.11 & 3.70 & & \\
\hline Street connectivity & 0.13 & -0.74 & & \\
\hline Neighborhood aesthetics & 0.11 & 0.64 & & \\
\hline Traffic safety & 1.93 & -1.38 & & \\
\hline Walk/cycle facilities & -2.43 & -1.29 & & \\
\hline Proximity to stores & 2.74 & 1.33 & & \\
\hline Proximity to play areas & 3.54 & 2.25 & $4.12^{*}[0.66-7.58]$ & $2.12^{*}[0.30-3.95]$ \\
\hline Barriers to walking/cycling: logistics & -2.17 & -2.10 & & \\
\hline Barriers to walking/cycling: route factors & -1.08 & 2.55 & & \\
\hline $\begin{array}{l}\text { Barriers to activity: perceived lack } \\
\text { of appropriate play areas }\end{array}$ & -5.35 & -3.15 & & \\
\hline Barriers to activity: crime & -1.27 & 2.85 & & \\
\hline Constant & & $357.08^{* *}$ & 353.85 [334.88 - 372.83] & 79.07 [68.22 - 89.93] \\
\hline
\end{tabular}

All values expressed as unstandardized $B$.

$\mathrm{GIS}=$ Geographic Information Systems data.

$* P<.05$.

** $P<.01$.

$(\mathrm{N}=711)$

Others have found that play area proximity is consistently related to physical activity (as reviewed in [2]). Perhaps this association with overall physical activity reflects the fact that, for children, such physical activity is more discretionary than other physical activity in which children engage (e.g., school-based physical activity) or that higher levels of physical activity are only generally reached by children routinely using such play areas. Having few significant environmental correlates of the overall measures of physical activity is a finding consistent with previous literature [2]. Environmental influences are expected to be specific to domain of physical activity, such as transport or recreation [26,33], or physical specific location, such as neighborhood or park [5]. Thus, total physical activity measures may underestimate the importance of individual neighborhood environmental factors, although are useful given the association with health outcomes. Measuring physical activity in specific contexts will provide more useful information to those agencies and programs attempting to institute environmental changes to increase activity in these contexts.

Notably though, access or proximity to recreation areas was related to all physical activity outcomes in the present study, whether location-specific or total, parent-reported or objectively measured. This impressive consistency in a literature characterized by inconsistency [2] suggests that proximal play areas could be a powerful influence on child physical activity, and that this may be a useful focal point for cities that are developing more active-friendly neighborhoods. Recreational physical activity is the dominant domain of activity for children, and children typically have very low levels of physical activity while indoors [34], so it is reasonable that having places to play near the home would emerge as an important correlate of physical activity. Conversely, lack of accessible places to play could be a very strong barrier to children's activity. 
Additional analyses are needed to examine whether objective or perceived built environment, or what combination of these, are more strongly related to children's physical activity and where that physical activity occurs. The length of time spent being active in specific locations would also provide added value. A longitudinal study design would make causality inferences between the predictors and activity outcomes more feasible to determine, as would natural experiments in which children's behavior is examined before and after environmental changes. The present study did not include objective location or environment data such as what can be measured using GPS and GIS, which would allow us to objectively measure actual distances to play locations relative to amount of activity, rather than relying on parental reports, some of which had low internal consistency.

Among study strengths, children from a diversity of neighborhoods were recruited from two distinct regions, and virtually all measures demonstrated good retest reliability. However, most children were from relatively affluent families, with representative but limited racial/ethnic diversity. The recruitment rate of this study was lower than in survey-only studies, likely due to the added burden of an office or in-home visit (to measure anthropometrics) and accelerometry, leading to self-selection bias of higher SES families. However, this higher SES does not seem to have resulted in abnormally high activity rates relative to a national sample $[35,36]$. Parental perception was a limiting factor in the assessment of the neighborhood environment, and measurements such as distances to parks and recreation areas were subjective and potentially prone to error. These analyses were limited to recreational activity and not transport activity, a potentially significant limitation given the substantial role that active transport by children to school can play in some neighborhoods and for their overall physical activity.

\section{Conclusion}

The present study identified multiple conceptuallycongruent neighborhood environment correlates of children's physical activity in neighborhoods and parks. Because these are the most common places for children to be active [9], and are also related to overall physical activity levels, these results have public health significance. If neighborhoods, parks, schools, private recreation facilities, and roadways can all be designed to optimize physical activity, then the cumulative effect could be expected to increase physical activity and reduce the risk of obesity and chronic diseases. Present results suggest that specific environmental changes may improve children's physical activity. However, these hypotheses need to be tested further. If confirmed, the evidence will provide justification and impetus for policy changes that will ensure more children live in environments that support active lifestyles. Proximity to play areas was related to all child physical activity outcomes in the present study, making this a high priority for further study and consideration of policy solutions to ensure all children have safe places to play near their homes.

\section{Competing interests}

The authors have indicated they have no conflicts of interest or financial relationships relevant to this article to disclose.

\section{Authors' contributions}

JS, BS and KG conceived the overall NIK study. JS and BS collected the data. $K G, B S$, and $K T$ conceptualized the manuscript. KT and $C Z$ analyzed the data. All authors have participated in drafting or revising of the manuscript; and all have approved the manuscript as submitted.

\section{Acknowledgements}

Many thanks go to the project leaders who worked so tirelessly to make this project happen: Trina Colburn, Project Coordinator at Seattle Children's Hospital; Kelli Cain and Carrie Geremia at San Diego State University and the NIK parents and children who participated.

This research was supported by National Institutes of Health, National Institute of Environmental Health Sciences ES14240.

\section{Author details}

${ }^{1}$ Department of Biostatistics and Epidemiology, Perelman School of Medicine, University of Pennsylvania, Philadelphia, USA. ${ }^{2}$ Current address: Department of Psychology, Rowan University, Glassboro, NJ, USA. ${ }^{3}$ Department of Biostatistics and Epidemiology, Perelman School of Medicine and School of Nursing, University of Pennsylvania, Philadelphia, USA. ${ }^{4}$ Department of Psychology, San Diego State University, San Diego, CA, USA. ${ }^{5}$ Current address: Department of Family and Preventive Medicine, University of California, San Diego, CA, USA. ${ }^{6}$ Seattle Children's Research Institute, P.O. Box 5371, Seattle, WA 98145, USA. ${ }^{7}$ Department of Pediatrics, School of Medicine, University of Washington, Seattle, USA.

Received: 12 June 2012 Accepted: 7 March 2013

Published: 27 March 2013

\section{References}

1. Committee on Environmental Health: The built environment: Designing communities to promote physical activity in children. Pediatrics 2009, 123:1591-1598.

2. Ding D, Sallis JF, Kerr J, Lee S, Rosenberg DE: Neighborhood environment and physical activity among youth: A review. Am J Prev Med 2011, 41:442-455.

3. Impact of the built environment on health. http://www.cdc.gov/nceh/ publications/factsheets/ImpactoftheBuiltEnvironmentonHealth.pdf.

4. Sallis J, Glanz K: The role of built environments in physical activity, eating, and obesity in childhood. Future Child 2006, 16:89-108.

5. Davison K, Lawson C: Do attributes in the physical environment influence children's physical activity. A review of the literature. Int J Behav Nutr Phys Act 2006, 3:19

6. De Vet E, De Ridder DTD, De Wit JBF: Environmental correlates of physical activity and dietary behaviours among young people: A systematic review of reviews. Obes Rev 2010, 12(5):e130-142.

7. Boarnet M, Anderson C, Day K, McMillan T, Alfonzo M: Evaluation of the California Safe Routes to School legislation: Urban form changes and children's active transportation to school. Am J Prev Med 2005, 28:134-140.

8. Ewing R, Schroeer W, Greene W: School location and student travel. Transp Res Rec 1895, 2004:55-63.

9. Grow HM, Saelens BE, Kerr J, Durant NH, Norman GJ, Sallis JF: Where are youth active? Roles of proximity, active transport, and built environment. Med Sci Sports Exerc 2008, 40:2071-2079.

10. Burdette $\mathrm{HL}$, Whitaker RC: A national study of neighborhood safety, outdoor play, television viewing, and obesity in preschool children. Pediatrics 2005, 116:657-662

11. Sallis J, Conway T, Prochaska J, McKenzie T, Marshall M, Brown M: The association of school environments with youth physical activity. Am J Pub Health 2001, 91:618-620.

12. Frank LD, Saelens BE, Chapman J, Sallis JF, Kerr J, Glanz K, Couch SC, Learnihan V, Zhou C, Colburn T, Cain KL: Objective assessment of obesogenic environments 
in youth: Geographic information system methods and spatial findings from the Neighborhood Impact on Kids study. Am J Prev Med 2012, 42:e47-e55.

13. Corder K, Ekelund U, Steele RM, Wareham NJ, Brage S: Assessment of physical activity in youth. J Appl Physio/ 2008, 105:977-987.

14. Trost SG, Way R, Okely AD: Predictive validity of three ActiGraph energy expenditure equations for children. Med Sci Sports Exerc 2006, 38:380-387.

15. Trost SG, Loprinzi PD, Moore R, Pfeiffer KA: Comparison of accelerometer cut points for predicting activity intensity in youth. Med Sci Sports Exerc 2011, 43:1360-1368.

16. Saelens lab measures and protocols. http://www.seattlechildrens.org/research/ child-health-behavior-and-development/saelens-lab/measures-and-protocols/.

17. Rosenberg DE, Sallis JF, Kerr J, Maher J, Norman GJ, Durant N, Harris SK, Saelens BE: Brief scales to assess physical activity and sedentary equipment in the home. Int J Behav Nutr Phys Act 2010, 7:10.

18. Cerin E, Saelens B, Sallis J, Frank L: Neighborhood Environment Walkability Scale: Validity and development of a short form. Med Sci Sports Exerc 2006, 38:1682-1691

19. Rosenberg D, Ding D, Sallis JF, Kerr J, Norman GJ, Durant N, Harris SK, Saelens BE: Neighborhood Environment Walkability Scale for Youth (NEWS-Y): Reliability and relationship with physical activity. Prev Med 2009, 49:213-218.

20. Durant N, Kerr J, Harris SK, Saelens BE, Norman GJ, Sallis JF: Environmental and safety barriers to youth physical activity in neighborhood parks and streets: Reliability and validity. Pediatr Exerc Sci 2009, 21:86-99.

21. Scoring for the Neighborhood Environment Walkability Scale - Youth (NEWS-Y). http://sallis.ucsd.edu/measure_news.html.

22. Prochaska JJ, Sallis JF, Long B: A physical activity screening measure for use with adolescents in primary care. Arch Pediatr Adolesc Med 2001, 155:554-559.

23. Frank LD, Sallis JF, Saelens BE, Leary L, Cain K, Conway TL, Hess PM: The development of a walkability index: Application to the neighborhood quality of life study. Br J Sports Med 2009, 44:924-933.

24. Saelens BE, Frank LD, Auffrey C, Whitaker RC, Burdette HL, Colabianchi N: Measuring physical environments of parks and playgrounds: EAPRS instrument development and inter-rater reliability. J Phys Act Health 2006, 3:S190-\$207.

25. Kline RB: Principles and Practice of Structural Equation Modeling. 2nd edition. New York, NY: Guilford; 2005.

26. Giles-Corti B, Timperio A, Bull F, Pikora T: Understanding physical activity environmental correlates: Increased specificity for ecological models. Exercise and Sport Science Reviews 2005, 33:175-1181.

27. Sallis J, Cervero RB, Ascher W, Henderson KA, Kraft MK, Kerr J: An ecological approach to creating active living communities. Annu Rev Pub Health 2006, 27:297-322.

28. Mecredy G, Janssen I, Pickett W: Neighbourhood street connectivity and injury in youth: A national study of built environments in Canada. Inj Prev 2011, 18:81-87.

29. Giles-Corti B, Wood G, Pikora T, Learnihan V, Bulsara M, Van Niel K, Timperio A, McCormack G, Villanueva K: School site and the potential to walk to school: The impact of street connectivity and traffic exposure in school neighborhoods. Health Place 2011, 17:545-550.

30. Saelens BE, Handy SL: Built environment correlates of walking: A review. Med Sci Sports Exerc 2008, 40:S550-566.

31. Limstrand T: Environmental characteristics relevant to young people's use of sports facilities: A review. Scand J Med Sci Sports 2008, 18:275-287.

32. Evenson KR, Scott MM, Cohen DA, Voorhees CC: Girls' perception of neighborhood factors on physical activity, sedentary behavior, and BMI. Obesity 2007, 15:430-445

33. Saelens B, Sallis J, Frank L: Environmental correlates of walking and cycling: Findings from the transportation, urban design, and planning literatures. Ann Behav Med 2003, 25:80-91.

34. Troiano RP, Berrigan D, Dodd KW, Masse LC, Tilert T, McDowell M: Physical activity in the United States measured by accelerometer. Med Sci Sports Exerc 2008, 40:181-188.

35. Sallis J, Prochaska J, Taylor W: A review of correlates of physical activity of children and adolescents. Med Sci Sports Exerc 2000, 32:963-975.

36. Nader PR, Bradley RH, Houts RM, McRitchie SL, O'Brien M: Moderate-to-vigorous physical activity from ages 9 to 15 years. JAMA 2008, 300:295-305.

doi:10.1186/1479-5868-10-39

Cite this article as: Tappe et al:: Children's physical activity and parents' perception of the neighborhood environment: neighborhood impact on kids study. International Journal of Behavioral Nutrition and Physical Activity 2013 10:39.

\section{Submit your next manuscript to BioMed Central and take full advantage of:}

- Convenient online submission

- Thorough peer review

- No space constraints or color figure charges

- Immediate publication on acceptance

- Inclusion in PubMed, CAS, Scopus and Google Scholar

- Research which is freely available for redistribution 